\title{
Relative Technical Efficiency of Life Insurance Companies DEA and Interval DEA Methods
}

\author{
S. Jasmine Rathi, V. Prakash
}

\begin{abstract}
Insurance industries in India have taken a huge shape especially after privatization and introduction of Insurance Regulatory \& Development Authority (IRDA). It plays an vital role in the growth of financial sector in all developed and developing countries. Insurance may be a sort of risk management and primarily used hedge against the danger of a contingent or uncertain loss. In this paper the author analyses the relative efficiency of life insurance companies in India using DEA and Interval Data Envelopment Approach (Interval $D E A) . D E A$ is a non parametric linear programming problem used for measuring the relative efficiency of decision making units (DMU) which utilize several identical inputs to produce a set of identical outputs. Interval DEA model is used in efficiency measurement of the life insurance companies under imprecise inputs and outputs. The empirical results of the conventional DEA models and Interval DEA models are computed to trace the performance of decision making unit at a possibility level.
\end{abstract}

Keywords:Data Envelopment Analysis (DEA), Fuzzy data, Interval Data Envelopment Analysis (Interval DEA), Interval Efficiency, Life insurance Companies.

\section{INTRODUCTION}

Insurance industries in India have taken a huge shape especially after privatization and introduction of Insurance Regulatory \& Development Authority (IRDA). Insurance means protection from financial loss. The role of insurance is to help their policyholders to manage the risk efficiently and paying the claims covered by their insurance policies. Function of insurance act as risk transfer mechanism to provide peace of mind and protect against losses. Life insurance provides a monetary benefit to a person who is no longer living or other designated beneficiary, and can specifically provide for income to an insured person's family, It lower the total risk faced by an economy through risk diversification across border as well as to promote risk mitigation activities.

Data Envelopment Analysis is a non parametric linear programming problem used to measure the relative efficiency of decision making units (DMU) which utilize several identical inputs to produce a set of identical outputs. Each organization is termed as decision making units. Conventional DEA models, such as CCR and BCC models can only deals with exact data. To deal with imprecise inputs and outputs fuzzy numbers or interval data is used.

A pair of interval DEA models were developed for interval input and output data rather than for crisp input and output data. The efficiency score for each life insurance companies were obtained by the bounded interval for the best lower bound efficiency and for the best upper bound efficiency of each DMU, which is referred as Interval Efficiency.

Revised Manuscript Received on December 5, 2019.

S. Jasmine Rathi, Department of Statistics, Presidency College, Chennai, Tamil Nadu, India

V. Prakash, Associate Professor, Department of Statistics, Presidency College, Chennai, Tamil Nadu, India
The objective of this study is to analyse the relative efficiency of life insurance companies for the financial year 2018- 2019 using Conventional DEA and Interval DEA models. To attain these objectives the author considered 24 life insurance companies which is obtained from the annual report published by The Insurance Regulatory and Development Authority of India (IRDA). The rest of this paper is organized as follows: Section II deals with the Review of literature. III describe the Data Structure, Methodology is presented in Section IV, Empirical Investigations are carried out in Section $\mathrm{V}$ and Findings and Conclusions are outlined in Section VI.

\section{REVIEW OF LITERATURE}

Farrel, .M.J. (1957) developed the basic measure of efficiency in case of single input and single output. Zadeh, L.A. (1965) proposed a Fuzzy DEA model to deal with imprecise and vague data and is used for all kinds of input and output under fuzzy numbers. Charnes, A.,W.W. Cooper, E. Rhodes (1978), proposed the efficiency of decision making units which is defined as the maximum of a ratio of weighted sum of outputs to weighted sum of inputs subject to the conditions that the same ratio for all DMUs must be less than or equal to one. It is based on the assumption of constant returns to scale. R.D.Banker, A.Charnes, W.W.Cooper (1984) extended the CCR model and proposed a new model for estimating pure technical efficiency of decision making units with reference to efficient frontier and this model admits variable returns to scale. Sengupta (1992) introduced the use of fuzzy set theory on DEA models by applying the concept of fuzzy linear programming to allow the fuzzy nature of objective function and constrains on the CCR model under condition of imprecise data. According to Zadeh's extension principle Yager 1986, Zadeh 1978, Zimmermann 1996 defined the membership function of kth DMU. Kao,C. And Liu, S.T., (2000) generated a fuzzy efficiency measurement to transform a parametric program by using $\alpha$ - cut approach. Kao, C., Liu, S.T.(2003) developed a method to rank the fuzzy efficiency score without the exact membership function. HuseyinBudak, SemraErpolat (2013) applied an interval DEA approach to find the efficiency measurements of Turkish banking sector with interval data and conclude that interval DEA methods provides more selective results than DEA. Sara Bray, Leonardo Caggiani and Michele Ottomanelli (2015) evaluates the transport system efficiency using fuzzy DEA and traditional DEA approach, from the results it is observed that fuzzy DEA approach makes the efficiency estimation more accurate and realistic. UmiMahmudah, Muhamad Safiih Lola (2016) measured the efficiency of Indonesian universities using DEA and FDEA approach and the results indicates that the well known universities have shown relatively low scores and also VRS model is better in 
both DEA and FDEA models.Stefanos A. Nastis, Thomas Bournaris, DimitriosKarpouzos (2017) estimates the efficiency score of organic farms obtained by fuzzy dea to compare with conventional DEA and conclude that there is a little evidence of symmetrical bias found in the sample and also the results are more robust by using $\alpha$-cut level. Ali Namakin, SeyyedEsmaeilNajafi, Mohammad Fallah and MehrdadJavadi (2018) used a new approach based on crisp linear programming and proved that the existing method to solve FFDEA with $\mathrm{Z}$-numbers is not valid. The result indicates that the proposed method provides the right evaluation of the relative efficiency of a DMU under ambiguous circumstances and gives more reliable results. Pejman Peykani, Emran Mohammadi, Ali Emrouznejad, Mir Saman Pishvaee, Mohsen Rostamy - Malkhalifeh (2019) proposed a novel fuzzy DEA models based on general fuzzy measure in which the DMUs are determined by optimistic and pessimistic parameters. It infers that the proposed FDEA model is applicable, flexible and adjustable based on each DMU.

\section{DATA STRUCTURE}

The data used in this study is a secondary source which is obtained from the Annual report of life insurance companies published by The Insurance Regulatory and Development Authority of India (IRDAI). The sample consists of 24 Life Insurance Companies covering all over India. The study relates to a period of 2018 - 2019. Each life insurance company is considered as a Decision Making Unit and it includes three inputs and three outputs are described below:

\begin{tabular}{|c|c|}
\hline Inputs (in Crores) & Outputs ( in Crores) \\
\hline Operating expenses & Net Premium \\
\hline Policy Liabilities & Income from Investment \\
\hline Fixed Asset & $\begin{array}{c}\text { Investments (share holders \& } \\
\text { policy holders) }\end{array}$ \\
\hline
\end{tabular}

\section{METHODOLOGY}

The basic DEA model is developed by Charnes, Cooper, Rhodes (1978) known as CCR model and it is based on constant return to scale (CRS) assumption. Further the model was extended by Banker Charnes Cooper (1984) known as BCC model and they introduced the new variable $\mathrm{u}_{0}$ in BCC modelwhich admits variable return to scale. Let $\boldsymbol{\theta}_{\mathrm{k}}$ is the efficiency measure of $\mathrm{k}^{\text {th }}$ DMU. $\mathrm{u}_{\mathrm{r}}$ is the weight attached to the $\mathrm{r}^{\text {th }}$ output and $\mathrm{v}_{\mathrm{i}}$ is the weight attached to the $\mathrm{m}^{\text {th }}$ inputs for the $\mathrm{j}^{\text {th }}$ DMU. $\mathrm{Y}_{\mathrm{rk}}$ is the output $\mathrm{r}$ produced by $\mathrm{j}^{\text {th }}$ DMU. $\mathrm{X}_{\mathrm{ij}}$ is the input $\mathrm{i}$ utilized by $\mathrm{j}^{\text {th }} \mathrm{DMU}, \mathrm{i}=1$ to $\mathrm{m}$ (number of input), $r=1$ to $p$ (number of output), $j=1$ to $n$ (number of DMU) and $\mathrm{u}_{0}$ is the dual variable admitting variable returns to scale. Both $\mathrm{CCR}$ and $\mathrm{BCC}$ models are presented below.

\section{Model 1}

CCR Multiplier Model (output-maximization)

$$
\begin{aligned}
& \max \theta_{\mathrm{k}}=\sum_{r=1}^{p} \mathrm{u}_{\mathrm{r}} \mathrm{y}_{\mathrm{rk}} \\
& \sum_{i=1}^{m} \mathrm{v}_{\mathrm{i}} \mathrm{x}_{\mathrm{ij}}=1 \\
& \sum_{r=1}^{p} \mathrm{u}_{\mathrm{r}} \mathrm{y}_{\mathrm{rk}}-\sum_{i=1}^{m} \mathrm{v}_{\mathrm{i}} \mathrm{x}_{\mathrm{ij}} \leq 0 ; j=1,2 \ldots, n \\
& \mathrm{u}_{\mathrm{r}}, \mathrm{v}_{\mathrm{i}}, \geq \in ; \quad r=1,2, \ldots, p \text { and } i=1,2, \ldots, m
\end{aligned}
$$

\section{Model 2}

$\underline{\text { BCC Multiplier Model (output-maximization) }}$

$$
\begin{aligned}
& \max \theta_{\mathrm{k}}= \sum_{r=1}^{p} \mathrm{u}_{\mathrm{r}} \mathrm{y}_{\mathrm{rk}}+\mathrm{u}_{0} \\
& \sum_{i=1}^{m} \mathrm{v}_{\mathrm{i}} \mathrm{x}_{\mathrm{ij}}=1 \\
& \sum_{r=1}^{p} \mathrm{u}_{\mathrm{r}} \mathrm{y}_{\mathrm{rk}}-\sum_{i=1}^{m} \mathrm{v}_{\mathrm{i}} \mathrm{x}_{\mathrm{ij}}+\mathrm{u}_{0} \leq 0 ; j=1,2 . ., n \\
& \mathrm{u}_{\mathrm{r}}, \mathrm{v}_{\mathrm{i}}, \geq \in ; \quad r=1,2, \ldots, p \text { and } i=1,2, \ldots, m
\end{aligned}
$$

where $\epsilon$ is a small positive quantity or infinitesimal constant. Crisp input and output are fundamentally indispensable in Conventional DEA. However the observed value of the input and output data in real world situations are sometimes imprecise or vague. Due to the uncertainty, the data have complex input and output so we use the concept of fuzzy parametric programming to deal with DEA framework under fuzzy environment. (Despotis and Smirlis, 2002) and (Wang et al, 2005) generated the following models to create lower and upper bounds of interval efficiency of each DMU in order to mention the uncertainty state in the condition that was known to locate between lower and upper bounds $\left[x_{i j}^{L}, x_{i j}^{U}\right]$ and [ $\left.y_{r j}^{L}, y_{r j}^{U}\right]$ where $x_{i j}^{L}>0$ and $y_{r j}^{L}>0$. Lower and Upper bound of the fuzzy inputs $\tilde{X}_{\mathrm{ij}}=\left(x_{i j}^{L}, x_{i j}^{M}, x_{i j}^{U}\right)$ and fuzzy outputs $\tilde{Y}_{\mathrm{rj}}=($ $\left.y_{r j}^{L}, y_{r j}^{M}, y_{r j}^{U}\right)$ are determined by

$$
\begin{aligned}
& \tilde{X}_{\mathrm{ij}}=\left(\alpha x_{i j}^{M}+(1-\alpha) x_{i j}^{L}, \alpha x_{i j}^{M}+(1-\alpha) x_{i j}^{U}\right) \\
& \tilde{Y}_{\mathrm{rj}}=\left(\alpha y_{r j}^{M}+(1-\alpha) y_{r j}^{L}, \alpha y_{r j}^{M}+(1-\alpha) y_{r j}^{U}\right)
\end{aligned}
$$


Model 3

$$
\begin{aligned}
& \max \theta_{k}^{L}= \sum_{r=1}^{p} \mathrm{u}_{\mathrm{r}} y_{r k}^{L} \\
& \sum_{i=1}^{\mathrm{m}} \mathrm{v}_{\mathrm{i}} x_{i k}^{U}=1 \\
& \sum_{r=1}^{p} \mathrm{u}_{\mathrm{r}} y_{r j}^{L}-\sum_{i=1}^{\mathrm{m}} \mathrm{v}_{\mathrm{i}} x_{i j}^{U} \leq 0, \mathrm{j}=1 . ., \mathrm{n} \\
& \mathrm{u}_{\mathrm{r}}, \mathrm{v}_{\mathrm{i}} \geq \in, \quad \forall \mathrm{r}, \mathrm{i}
\end{aligned}
$$

Model 4

$$
\begin{aligned}
& \max \theta_{k}^{U}= \sum_{r=1}^{p} \mathrm{u}_{\mathrm{r}} y_{r k}^{U} \\
& \sum_{i=1}^{\mathrm{m}} \mathrm{v}_{\mathrm{i}} x_{i k}^{L}=1 \\
& \sum_{r=1}^{p} \mathrm{u}_{\mathrm{r}} y_{r j}^{U}-\sum_{i=1}^{\mathrm{m}} \mathrm{v}_{\mathrm{i}} x_{i j}^{L} \leq 0, \mathrm{j}=1 . ., \mathrm{n} \\
& \mathrm{u}_{\mathrm{r}}, \mathrm{v}_{\mathrm{i}} \geq \epsilon, \quad \forall \mathrm{r}, \mathrm{i}
\end{aligned}
$$

Interpretation of $\theta_{\mathrm{j}} \mathrm{u}_{\mathrm{r}}, \mathrm{v}_{\mathrm{i}} \mathrm{y}_{\mathrm{rk}}, \mathrm{x}_{\mathrm{ij}}$ are similar to the basic DEA models. It may be noted that the above models obtains the efficiency intervals for each DMU. Further to calculate the efficiency score for each interval at different level of $\alpha$ the following $\alpha$ - cut level approach fuzzy DEA model is used.

Model 5

$$
\begin{aligned}
&\left(\theta_{\mathrm{k}}\right)_{\alpha}^{L}= \max \sum_{r=1}^{p} \mathrm{u}_{\mathrm{r}}\left(\mathrm{Y}_{\mathrm{rk}}\right)_{\alpha}^{\mathrm{L}} \\
& \sum_{i=1}^{\mathrm{m}} \mathrm{v}_{\mathrm{i}}\left(\mathrm{X}_{\mathrm{ik}}\right)_{\alpha}^{\mathrm{U}}=1 \\
& \sum_{r=1}^{p} \mathrm{u}_{\mathrm{r}}\left(\mathrm{Y}_{\mathrm{rk}}\right)_{\alpha}^{\mathrm{L}}-\sum_{i=1}^{\mathrm{m}} \mathrm{v}_{\mathrm{i}}\left(\mathrm{X}_{\mathrm{ik}}\right)_{\alpha}^{\mathrm{U}} \leq 0, \quad \mathrm{j}=1 \ldots, \mathrm{n} \\
& \sum_{r=1}^{p} \mathrm{u}_{\mathrm{r}}\left(\mathrm{Y}_{\mathrm{rj}}\right)_{\alpha}^{\mathrm{U}}-\sum_{i=1}^{\mathrm{m}} \mathrm{v}_{\mathrm{i}}\left(\mathrm{X}_{\mathrm{ij}}\right)_{\alpha}^{\mathrm{L}} \leq 0, \quad \mathrm{i} \neq \mathrm{j} \\
& \mathrm{u}_{\mathrm{r}}, \mathrm{v}_{\mathrm{i}} \geq \in, \geq 0
\end{aligned}
$$

\begin{tabular}{|c|c|c|}
\hline DMUs & CRS & VRS \\
\hline Aviva & 1.000 & 1.000 \\
\hline HDFC life & 0.917 & 1.000 \\
\hline Birla Sun & 0.942 & 0.955 \\
\hline ICICI Prudential & 0.356 & 0.852 \\
\hline Kotak & 0.947 & 1.000 \\
\hline India First & 1.000 & 1.000 \\
\hline LIC & 1.000 & 1.000 \\
\hline Aegon & 1.000 & 1.000 \\
\hline Shriram & 0.838 & 0.848 \\
\hline IDBI Federal & 0.971 & 1.000 \\
\hline Sahara & 1.000 & 1.000 \\
\hline Edelweiss & 1.000 & 1.000 \\
\hline SBI & 1.000 & 1.000 \\
\hline Max Life & 1.000 & 1.000 \\
\hline Exide & 1.000 & 1.000 \\
\hline Tata aia & 0.945 & 0.964 \\
\hline DHFL Pramerica & 1.000 & 1.000 \\
\hline Canara HSBC & 1.000 & 1.000 \\
\hline Bajaj Allianz & 1.000 & 1.000 \\
\hline Bharti Axa & 1.000 & 1.000 \\
\hline Future Generali & 0.757 & 0.784 \\
\hline Reliance Nippon & 1.000 & 1.000 \\
\hline Star Union & 0.878 & 0.880 \\
\hline PNBmet & 0.780 & 0.781 \\
\hline Avg. Efficiency Score & 0.930 & 0.961 \\
\hline
\end{tabular}

Model 6

$$
\begin{aligned}
\left(\theta_{\mathrm{k}}\right)_{\alpha}^{U}= & \max \sum_{r=1}^{p} \mathrm{u}_{\mathrm{r}}\left(\mathrm{Y}_{\mathrm{rk}}\right)_{\alpha}^{\mathrm{U}} \\
& \sum_{i=1}^{\mathrm{m}} \mathrm{v}_{\mathrm{i}}\left(\mathrm{X}_{\mathrm{ik}}\right)_{\alpha}^{\mathrm{L}}=1 \\
& \sum_{r=1}^{p} \mathrm{u}_{\mathrm{r}}\left(\mathrm{Y}_{\mathrm{rk}}\right)_{\alpha}^{\mathrm{U}}-\sum_{i=1}^{\mathrm{m}} \mathrm{v}_{\mathrm{i}}\left(\mathrm{X}_{\mathrm{ik}}\right)_{\alpha}^{\mathrm{L}} \leq 0, \quad \mathrm{j}=1 \ldots, \mathrm{n} \\
& \sum_{r=1}^{p} \mathrm{u}_{\mathrm{r}}\left(\mathrm{Y}_{\mathrm{rj}}\right)_{\alpha}^{\mathrm{L}}-\sum_{i=1}^{\mathrm{m}} \mathrm{v}_{\mathrm{i}}\left(\mathrm{X}_{\mathrm{ij}}\right)_{\alpha}^{\mathrm{U}} \leq 0, \quad \mathrm{i} \neq \mathrm{j}
\end{aligned}
$$$$
\mathrm{u}_{\mathrm{r}}, \mathrm{v}_{\mathrm{i}} \geq \in, \geq 0
$$

\section{EMPIRICAL INVESTIGATION}

Empirical investigation for the data structure presented in section III is carried out and the results are presented below. Efficiency scores of Conventional DEA model and Interval DEA model at $\alpha=0.50$ are placed in Table 1a and Table $1 \mathrm{~b}$.

Table 1a: Efficiency Score of Conventional DEA Model

Table 1b: Efficiency Score of Interval DEA Model

\begin{tabular}{|c|c|c|}
\hline DMUs & Lower Bound & Upper Bound \\
\hline Aviva & 0.1028 & 1.0000 \\
\hline HDFC life & 0.0576 & 0.3425 \\
\hline Birla Sun & 0.1142 & 0.4153 \\
\hline ICICI Prudential & 0.0615 & 0.1579 \\
\hline Kotak & 0.0607 & 0.2185 \\
\hline India First & 0.3294 & 0.8761 \\
\hline LIC & 0.0063 & 0.1610 \\
\hline Aegon & 0.0258 & 1.0000 \\
\hline
\end{tabular}




\section{Relative Technical Efficiency of Life Insurance Companies DEA and Interval DEA Methods}

\begin{tabular}{|c|l|l|}
\hline Shriram & 0.0113 & 1.0000 \\
\hline IDBI Federal & 0.0304 & 0.2724 \\
\hline Sahara & 0.0148 & 1.0000 \\
\hline Edelweiss & 0.0295 & 1.0000 \\
\hline SBI & 0.1094 & 0.1882 \\
\hline Max Life & 0.0246 & 0.3498 \\
\hline Exide & 0.0396 & 0.0729 \\
\hline Tata aia & 0.3478 & 1.0000 \\
\hline DHFL Pramerica & 0.2124 & 1.0000 \\
\hline Canara HSBC & 0.0495 & 1.0000 \\
\hline Bajaj Allianz & 1.0000 & 1.0000 \\
\hline Bharti Axa & 0.0720 & 1.0000 \\
\hline Future Generali & 0.0043 & 0.1284 \\
\hline Reliance Nippon & 1.0000 & 1.0000 \\
\hline Star Union & 0.0146 & 0.3128 \\
\hline PNBmet & 0.0907 & 0.1335 \\
\hline
\end{tabular}

upper bound efficiency in Interval DEA approach. So we conclude that Interval DEA methods provide more selective results rather than Conventional DEA method.

\section{REFERENCES}

1. Ali Namakin, SeyyedEsmaeilNajafi, Mohammad Fallah and MehrdadJavadi (2018), "A New Evaluation for Solving the Fully Fuzzy Data Envelopment Analysis with Z-Numbers", Symmetry 2018, 10, 384; doi:10.3390/sym10090384

2. Banker, R.D., Charnes, A. and Cooper, W.W. (1984.), "Some models for estimating technical and scale inefficiencies in data envelopment analysis". Management Science 30(9):1078-192.

3. Bellman, R.E., Zadeh, L.A., (1970). Decision-making in a fuzzy environment, Management Science, 17B, 141-164.

4. Charnes, A., Cooper, W.W., Rhodes, E., (1978). "Measuring the efficiency of decision making units".European Journal of Operational Research 2(6):429-444.

5. Cooper, W. W., Seiford, L.M., Tone, K., and Zhu, J. (2007). "Some models and measures for evaluating performances with DEA: past accomplishments and future prospects". Journal of Productivity Analysis 28:151-164.

The Table 1a reveals that on an average the set of life insurance companies included in this study are $93 \%$ efficient under CRS model and 96\% efficient under VRS model. Under CRS model, on the whole 14 insurance companies namely Aviva Life, India First Life, LIC, Aegon Life, Sahara Life, Edelweiss Life, SBI Life, MAX Life, Exide Life, DHFL Pramerica Life, Canara HSBC, Bajaj Allianz Life, Bharti Ax Life and Reliance Nippon Life are 100\% efficient in maximizing their output with the given level of input.

VRS model indicates 17 Life Insurance companies namely Aviva Life, HDFC Life, Kotak Life, India First Life, LIC,Aegon Life, IDBI Federal Life, Sahara Life, Edelweiss Life, SBI Life, Max Life, Exide Life,DHFL Pramerica Life, Canara HSBC Life,Bajaj Allianz Life, Bharti Axa Life and Reliance Nippon Life are performing with $100 \%$ efficiecy. Rest of the insurance companies need to maximize their output to attain their efficiency.

From the above Table $1 \mathrm{~b}$ it may be observed that in Interval DEA approach 11 Lifelinsurance companies namely Aviva life,Aegon Life, Shriram Life, Sahara Life, Edelweiss Life, Tata aia Life, DHFL Pramerica Life, Canara HSBC Life, Bajaj Allianz life, Bharti AXA and Reliance Nippon have secured upper bound efficiency score equals to one. Also it may be noted that two insurance companies such as Bajaj Allianz Life and Reliance Nippon Life have secured lower bound efficiency score as unity as well as they perform efficiently in Conventional DEA and Interval DEA models.

\section{CONCLUSIONS}

Conventional DEA efficiency scores were obtained by exact data and Interval DEA efficiency scores were obtained for bounded data. The results of Conventional DEA model indicates that VRS model perform efficiently than CRS model. Interval DEA reveals that the following Life insurance companies like Aviva Life, Aegon Life, Sahara Life, Edelweiss Life, DHFL Pramerica Life, Canara HSBC Life and Bharti Axa Life which performs efficiently under Conventional DEA models have secured the best possible upper bound efficiency score but failed to secure lower bound efficiency score equals to one. We also observe that ShriramLife and Tata aia. Life insurance companies which does not attain efficiency in Conventional DEA model were found to be efficient in Interval DEA approach. Bajaj Allianz Life and Reliance Nippon Life perform efficiently both in Conventional DEA and Interval DEA models and all other efficient DMUs have become crisp in the best possible

6. Despotis, D.K. and Smirlis,Y.G. (2003), "Data envelopment analysis with imprecise data". European Journal of Operational Research 140(1):24-36.

7. Entani,T., Maeda,Y. and Tanaka, H. (2002), "Dual models of interval DEA and its extension to interval data", European Journal of Operational Research, Vol. 136, pp.32-45.

8. Farrell, M.J. (1957). "The measurement of productive efficiency".Journal of the Royal Statistical Society 120(3):253-290.

9. HuseyinBudak, SemraErpolat (2013) "Interval Data Envelopment Analysis And An Application In Turkish Banking Sector". European Scientific Journal 9(13):36-50

10. Kao, C., Liu, S.T. (2000a). "Fuzzy efficiency measures in data envelopment analysis". Fuzzy Sets and Systems 113(3):427-437.

11. Kao, C., Liu, S.T. (2003). "A mathematical programming approach to fuzzy efficiency ranking".International Journal of Production Economics 86(2):145-154.

12. PejmanPeykani, EmranMohammadi, Ali Emrouznejad, Mir SamanPishvaee, Mohsen Rostamy-Malkhalifeh (2019), "Fuzzy data envelopment analysis: An adjustable approach", Elsevier, https://doi.org/10.1016/j.eswa.2019.06.039

13. Ray, P. K. and Sahu, S. (1992), "Productivity measurement in multiproduct manufacturing firms: Evaluation and control through sensitivity analysis", International Journal of Production Economics, Vol. 28, No. 1, pp. 71-84

14. Saati, S., Memariani, A., Jahanshahloo, G. R. (2002). "Efficiency analysis and ranking of DMUs with fuzzy data". Fuzzy Optimization and Decision Making 1:255-267.

15. Sara Braya, Leonardo Caggiania, Michele Ottomanellia (2013) "Measuring transport systems efficiency under uncertainty by fuzzy sets theory based Data Envelopment Analysis: theoretical and practical comparison with traditional DEA model". Transportation Research Procedia 5:186-200

16. Sengupta, J. K. (1992). "A fuzzy systems approach in Data Envelopment Analysis".Computers and Mathematics with Applications 24(8-9):259-266.

17. Stefanos A. Nastis, Thomas Bournaris, DimitriosKarpouzos (2017), "Fuzzy data envelopment analysis of organic farms", Operational Research International Journal, DOI 10.1007/s12351-017-0294-9

18. Triantis, K. and Girod, O. (1998), "A mathematical programming approach for measuring technical efficiency in a fuzzy environment", Journal of Productivity Analysis, Vol. 10, pp. 85-102.

19. UmiMahmudah, Muhamad Safiih Lola (2016) "The Efficiency Measurement of Indonesian Universities Based on a Fuzzy Data Envelopment Analysis" Open Journal of Statistics 6:1050-1066

20. Wang, Y.M., Greatbanks, R. and Yang, J.B. (2005), "Interval efficiency assessment using data envelopment analysis". Fuzzy Sets and Systems 153(3):347-370.

21. Zadeh, L.A. (1965). "Fuzzy sets". Information and Control 8:338353.

22. Zhu, J. (2003), "Imprecise data envelopment analysis (IDEA): A review and improvement with an application". European Journal of Operational Research 144:513-529. 
23. Zimmermann, H.J. (1978). "Fuzzy programming and linear programming with several objective functions".Fuzzy Sets and Systems 1(1):45-55.

\section{AUTHORS PROFILE}

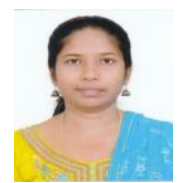

S. Jasmine Rathi a Research Scholar from Presidency College Chennai, received her M.Sc., M.Phil., in Statistics from University of Madras, Chennai Tamil Nadu, India. She has 12 years of enriched teaching experience from various reputed colleges in Chennai. Her area of specialization are Operation Research, Multivariate Analysis and Distribution Theory. She has published five research articles in National and International journals. She has also handled M.Sc. projects for the students.

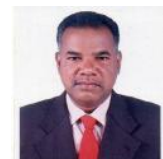

Dr. V. Prakash received his M.Sc., M.Phil., P.hd., in Statistics from University of Madras, Chennai, TamilNadu, India. Currently he is working as assistant professor and holding responsibility as Head, Department of Statistics, Presidency College, Chennai. He has totally 29 years of teaching experience in both UG and PG courses in Statistics. He has nearly 15 years of research experience and assisted $25 \mathrm{M}$.Sc. students to do their project work. He has guided and guiding M.Phil., and P.hd., scholars. So far 4 of his candidates were awarded P.hd., degree by University of Madras and still half a dozen persons carrying out their research under his guidance. His areas of specialization are Optimization Techniques, Data Envelopment Analysis and Stochastic Frontier Analysis. $\mathrm{He}$ has published more than 20 research articles in National and International reputed journal. He authored and acted as chairperson for Business Mathematics and Statistics Book for higher secondary students published by SCERT, Tamil Nadu text book society. 